\title{
Sellado de fluvisoles en la Comunidad de Madrid. Análisis a partir de imágenes landsat
}

\author{
Ma del Pilar GARcía RodRíGUEZ \\ Dpt. Análisis Geográfico Regional y Geografía Física \\ Universidad Complutense de Madrid \\ mpgarcia@ghis.ucm.es \\ Ma Eugenia PÉrez GonzÁlez \\ Dpt. Análisis Geográfico Regional y Geografía Física \\ Universidad Complutense de Madrid \\ meperez@ghis.ucm.es
}

Recibido: 23 de Noviembre de 2010

Enviado a evaluar: 3 de Marzo de 2011

Aceptado: 28 de Junio de 2011

\section{RESUMEN}

En este trabajo se analiza la evolución del sellado en los fluvisoles de la Comunidad de Madrid entre los años 1989 y 2009 utilizando imágenes del sensor TM del satélite Landsat. Estas imágenes permiten medir el área urbanizada en ambas fechas y conocer su distribución espacial. Se han seleccionado estos suelos por ser los más fértiles y porque su sellado implica un incremento en el riesgo de inundación en poblaciones muy próximas. La pérdida de suelo en estas dos décadas alcanza casi las 2.000 hectáreas. Las mayores superficies selladas corresponden a suelos agrológicamente ricos y muy ricos El sellado es extenso en las vegas de los ríos, Henares, Jarama y Tajo, y menor en los ríos Manzanares y Guadarrama.

Palabras clave: sellado, suelos, fluvisol, teledetección

\section{Fluvisol sealing in Madrid Community. Landsat images analysis}

\begin{abstract}
This paper analyses the evolution of the sealing of fluvisols in the Community of Madrid between 1989 and 2009. To do it images from TM sensor of Landsat have been used. These images allow us to measure the urban area on both dates and show its geographical distribution. These soils have been selected because they are the most fertile and the sealing has resulted in a higher risk of flooding in the nearby towns. Soil loss in two decades reached nearly 2000 hectares. The largest sealed areas are those which are rich or very rich agrologically. Sealing is widespread in the river valleys of the Henares, Jarama and Tagus rivers and not so much in the Manzanares and Guadarrama rivers.
\end{abstract}

Key words: sealed, soil, fluvisol, remote sensing 
Scellement de fluvisols dans Madrid.

Analyse des images de landsat

\section{RÉSUMÉ}

Cet article analyse l'évolution de fluvisoles scellé dans la Communauté de Madrid entre 1989 et 2009 à l'aide d'images du Landsat capteur TM. Ces images nous permettent de mesurer la zone urbaine sur les deux dates et montrer géographiques distribution. Ces sols ont été choisis pour être les plus fertiles et parce que les moyens d'étanchéité une augmentation du risque d'inondation dans les villes à proximité. La perte de sol en deux décennies a atteint près de 2.000 hectares. Les plus grandes zones sous sols scellés d'étanchéité agrologiques riche et très riche est très répandue dans les vallées fluviales, Henares, Jarama et du Tage, et plus bas dans la rivière du Manzanares et Guadarrama.

Mots clef: scellement, sol, fluvisol, télédétection

\section{INTRODUCCIÓN}

El sellado de suelos representa un grave problema, tanto por la desaparición de tierras fértiles, como por las implicaciones medioambientales que conlleva. Este problema es muy acusado en los países desarrollados, especialmente en las grandes ciudades y aglomeraciones urbanas de la costa (Castillo et al. 2004; García y Pérez, 2007, 2010 a y b). Además afecta con más frecuencia a los suelos más fértiles, ya que históricamente muchas poblaciones se asentaron en los valles de los ríos, edificando en sus llanuras de inundación, también ocupadas por las vías de comunicación a favor de los suelos con menor pendiente. En las últimas décadas la desaparición de estos suelos se ha acelerado a espaldas de la normativa existente, pese a los altos riesgos antrópicos y medioambientales que esto produce.

La Unión Europea se ha sensibilizado con este problema señalando la necesidad de establecer políticas de protección de suelos que limiten el sellado, especialmente de los suelos más fértiles (http://ec.europa.eu/environment/soil/ y http://www.eeb. org/). El conocimiento del suelo resulta un elemento clave en la planificación del territorio (Zinck, 1996 Añó y Sánchez, 2003 y Añó et al. 2005). Aunque numerosos autores han realizado investigaciones sobre el sellado del suelo en las proximidades de grandes ciudades y los efectos que producen, tanto por modificaciones en los diferentes elementos de los ecosistemas, como por costes sociales (Effland y Pouyat, 1997; Blum, 1998; Nizeyimana et al., 2001; Biasioli et al. 2006; Bouma, 2006 y Scalenghe y Ajmone-Marsan, 2009), apenas hay estudios de cuáles son los tipos de suelos más afectados por este sellado.

El sellado es un problema prácticamente irreversible y cuando afecta a suelos agrológicamente muy ricos éstos no tienen apenas posibilidades de recuperación, ya que aunque desapareciera la causa del sellado, todo el ecosistema ha quedado modificado (desaparición de microorganismos captadores de nitrógeno, pérdida de mesofauna asociada a distintos cultivos, etc.), por lo que es muy difícil que alcancen de nuevo valores altos de fertilidad.

El objetivo del presente estudio es analizar la desaparición de los suelos más ricos de la Comunidad de Madrid y cuantificar su efecto en los últimos 20 años. 
La disponibilidad de imágenes de satélites medioambientales desde los años ochenta permite conocer la evolución espacial del crecimiento urbano, industrial y de comunicaciones. Por ello se hace hincapié en la elaboración de cartografía que permita visualizar su localización y tipología. La mayor parte de estos suelos corresponden a unidades de fluvisoles, desarrollados en las vegas de los principales ríos de la Comunidad.

En la figura 1 se muestran dos imágenes TM de la Comunidad de Madrid: una, en la que se observan en tonos oscuros y tramado geométrico los principales núcleos urbanos y otra, en la que se han representado sólo los fluvisoles. La distribución espacial de estos suelos hace que su sellado implique un alto riesgo para las poblaciones que se asientan allí. Además, el sellado en áreas próximas a los cauces fluviales conduce a una disminución de la capacidad de infiltración del agua, incremento del hidromorfismo, aumento de la escorrentía y, por tanto, a un mayor riesgo de inundación.

Figura 1. Imagen Landsat del 06-05-2010 (5-3-1, R-V-A) y distribución de fluvisoles

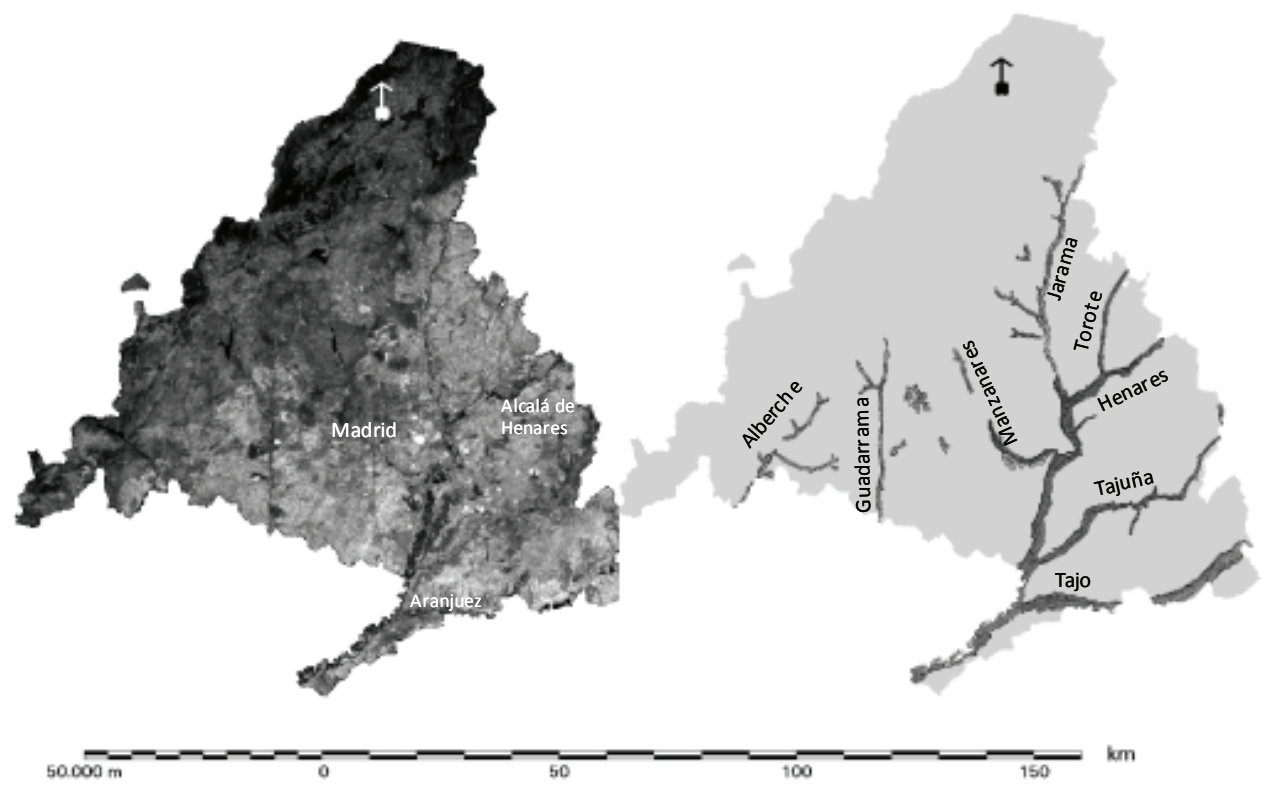

Fuente: IGN Plan Nacional de Teledetección 2010 y elaboración propia

Los fluvisoles son suelos poco evolucionados edáficamente, ya que se desarrollan sobre depósitos aluviales recientes. Tienen un gran riesgo de inundación, por lo que las construcciones sobre los mismos deberían estar seriamente limitadas. Sin embargo, en España existen numerosas construcciones situadas dentro del dominio público hidráulico y en áreas de alto riesgo de inundación. La mayoría son viviendas, pero hay otro tipo de instalaciones, como campings, polideportivos, áreas recreativas, 
centros de enseñanza, fábricas, naves industriales, etc. En la Comunidad de Madrid el riesgo de inundaciones tiene gran relevancia debido principalmente a la fuerte presión demográfica y socioeconómica. Así, la escasez de terrenos en muchas poblaciones y la especulación del suelo hacen que se invadan, con viviendas e industrias principalmente, cauces permanentes o no, ignorando o despreciando el riesgo de inundación y la legislación vigente. Una parte de estas construcciones se encuentran situadas en zonas de muy alto riego para las personas, en el caso de que se produzca una avenida. La urbanización de extensas áreas de terreno conduce a la disminución de la capacidad de infiltración del suelo, por lo que aumenta el caudal de descarga y disminuye el tiempo de concentración de las avenidas.

Existe un gran número de antecedentes sobre inundaciones históricas en la Comunidad de Madrid, que se recogen en un trabajo realizado por la Comisión Técnica de Inundaciones "Estudio de Inundaciones Históricas., Mapa de Riesgos Potenciales Cuenca del Tajo", del año 1985 (Jiménez, 2000). En toda la Cuenca del Tajo se recogen 159 antecedentes de inundaciones históricas, desde el año 849 hasta 1985. De ellas, 85 se localizan en la Comunidad de Madrid, lo que supone más de la mitad del total de toda la cuenca. Existe mayor número de referencias de aquellas inundaciones catastróficas, es decir, que dieron lugar a graves consecuencias humanas y/o económicas, mientras que de aquellas otras que apenas tuvieron consecuencias humanas y/o económicas casi no existen registros (Martínez, 2006). Por otra parte, en áreas que históricamente han tenido un gran desarrollo económico y social (Madrid, Alcalá de Henares y Aranjuez) se dispone de noticias escritas desde épocas muy remotas, mientras que otras zonas menos desarrolladas poseen menor cantidad de documentación, porque esta no se generó o se ha perdido. Los municipios que han sufrido mayores inundaciones históricas se sitúan en las cuencas de los ríos Tajo, Jarama y Henares, y son: Aranjuez (con 58 inundaciones), Alcalá de Henares (10), Madrid (6) y Paracuellos del Jarama (6).

El gran desarrollo urbanístico es el responsable de que el sellado sea la mayor causa de degradación de suelos en España. El auge de la construcción hasta el año 2008 ha conducido a un gran sellado en todos los núcleos urbanos. El elevado precio del suelo ha hecho que muchas de estas edificaciones se desplacen del centro de las ciudades a áreas periurbanas o núcleos próximos. A esto se añade el que la construcción de numerosas residencias secundarias incrementa el sellado del suelo, al ser éstas, viviendas unifamiliares que se extienden en amplias superficies y que en muchos casos llevan asociadas la construcción de otras infraestructuras: colegios, hoteles, polideportivos, etc.

\section{MATERIAL Y MÉTODOS}

Para analizar los cambios en el uso del suelo y el sellado del mismo se han utilizado las imágenes del sensor TM del satélite Landsat 5, con fechas del 25 de marzo de 1989 (NASA, 2009), 20 de junio de 2009 (IGN, 2009) y 6 de mayo de 
2010 (IGN, 2010). Corresponden a la escena 201-32. Son imágenes georreferidas y corregidas atmosféricamente. En ellas se han realizado mejoras espaciales, espectrales y radiométricas con el fin de detectar mejor los suelos sellados.

El software utilizado para el tratamiento de imágenes es ERDAS Imagine 2010.

En el estudio se han empleado también los mapas de Monturiol y Alcalá de asociaciones de suelos y capacidad potencial de uso agrícola de 1990. La escala de estos mapas 1:200.000 es la más adecuada para superponerla a las imágenes TM con resolución espacial de $30 \mathrm{~m}$.

Los procesos seguidos con las imágenes son:

1. Identificación en las imágenes TM de espacios construidos, seleccionando las combinaciones de bandas más adecuadas (canales visibles e infrarrojos próximo y medio, 5-3-1, 4-3-2, etc.), (Figura 1).

2. Extracción mediante polígonos de los suelos sellados en las dos fechas seleccionadas (1989 y 2009).

3. Georreferenciación de los mapas de suelos y de clases agrológicas de Monturiol y Alcalá (1990 a y b) para poderlos superponer a las imágenes de satélite.

4. Digitalización de polígonos correspondientes a los fluvisoles del mapa de suelos de Monturiol y Alcalá (1990 a) (Figura 1).

5. Digitalización de polígonos correspondientes a las clases agrológicas del mapa de Monturiol y Alcalá (1990 b).

6. Elaboración de mapas de fluvisoles sellados en 1989 y 2009 (Figura 2).

7. Elaboración de mapas de clases agrológicas selladas en ambas fechas (Figuras 3 y 4$)$.

8. Clasificaciones supervisadas con las diferentes clases de capacidades agrológicas de los suelos sellados. Para hacer las clasificaciones supervisadas se ha utilizado el algoritmo de máxima probabilidad, sin ninguna regla paramétrica ya que es el que ha mostrado mayor fiabilidad.

9. Evaluación de las clasificaciones supervisadas con la verdad terreno.

10. Cálculo de las diferencias del sellado de suelo entre las dos fechas seleccionadas (Figura 5).

\section{RESULTADOS Y DISCUSIÓN}

En la Comunidad de Madrid, los principales impactos sobre los suelos próximos a los cauces de los ríos corresponden al sellado por edificaciones (viviendas, infraestructuras viarias, etc) y a la extracción de áridos (tanto en el cauce del río como en los suelos de vega), lo que provoca alteraciones en el curso natural del agua, que implican graves riesgos para los asentamientos allí establecidos. Los ríos en los que estos problemas son más acusados son el Henares, Jarama, Manzanares, Tajo y Guadarrama. En la llanura de inundación del río Henares el mayor problema 
corresponde al sellado por crecimiento de naves industriales; en el Jarama, Manzanares y Tajo a construcciones industriales y residenciales y extracción de áridos, mientras que en el Guadarrama el sellado es debido casi siempre a construcción de viviendas e infraestructuras asociadas. Otros ríos como el Tajuña, Alberche, etc. también tienen problemas de sellado, aunque en menor medida. Incluso arroyos de segundo orden están afectados por este problema. En la figura 2 se representa el sellado de los fluvisoles en 1989 y 2009 en la que se observa el incremento de las superficies selladas entre ambas fechas. Se han elaborado a partir de las imágenes que combinen bandas visibles e infrarrojas, puesto que en ellas se discriminan mejor los suelos sellados. De todas ellas son las combinaciones 5-3-1 y 5-3-2 las que mejor los detectan.

Figura 2. Sellado de fluvisoles en 1989 y 2009

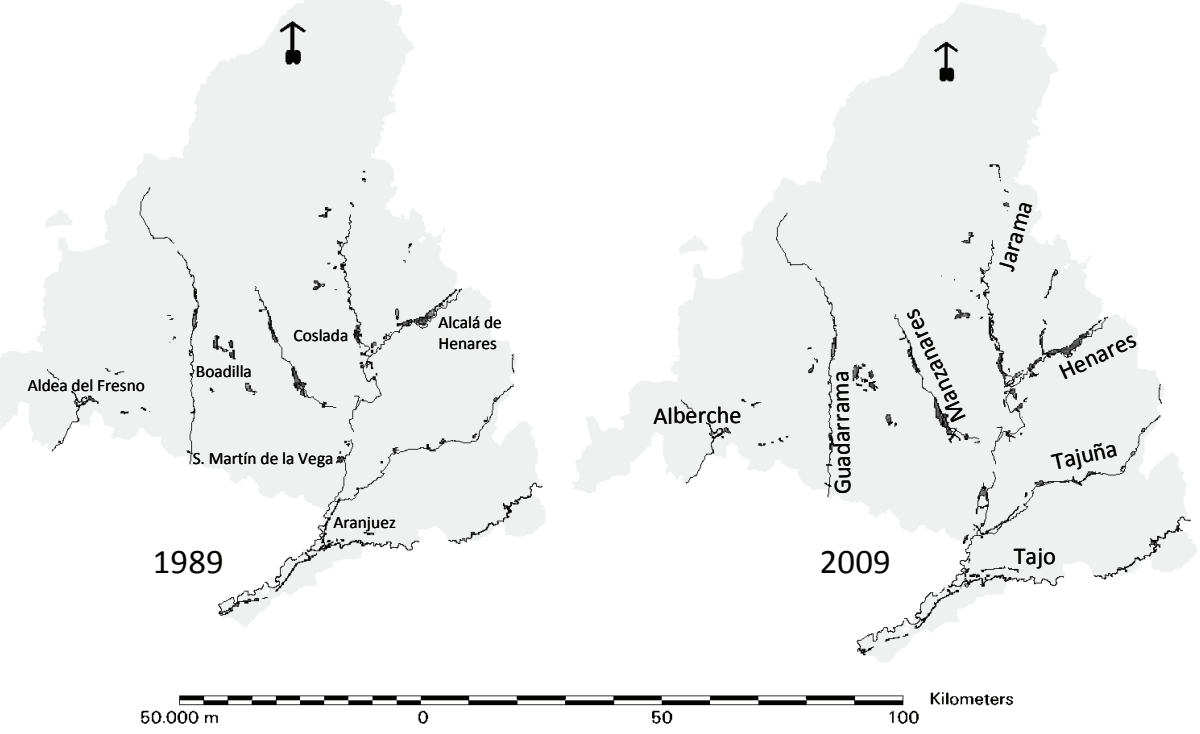

Fuente: elaboración propia

Los suelos más afectados por las inundaciones son los fluvisoles y en ellos los problemas de sellado son muy graves. Los fluvisoles son suelos poco evolucionados edáficamente, ya que se desarrollan sobre depósitos aluviales recientes, sin tiempo para alcanzar una mayor diferenciación. Salvo que estén afectados por problemas de hidromorfismo, son suelos muy fértiles. Sin embargo, su situación, en áreas llanas y cercanas a núcleos habitados, los hace muy vulnerables a la alteración antrópica.

Dentro de los fluvisoles en la Comunidad de Madrid sólo hay dos unidades con importancia cartográfica para formar asociaciones: fluvisoles eútricos y fluvisoles calcáricos. Estos últimos tienen mejores propiedades agronómicas. Ambos tienen un espesor superior a $100 \mathrm{~cm}$ y, en muchos casos, se desarrollan sobre graveras. La extensión de estos suelos en la Comunidad es pequeña pero tienen una enorme 
importancia económica (Monturiol y Alcalá, 1990 a). Están en las vegas de los ríos Henares, Jarama, Tajuña y Tajo y, en menor extensión, en las de los ríos Alberche, Torote, Guadarrama y Manzanares. Ocupan una extensión del 6,68\%, con una superficie total de $53.000 \mathrm{Ha}$. De ellas el 33,40\% corresponden a fluvisoles eútricos con un total de 17.700 hectáreas y el $66,60 \%$ a fluvisoles calcáricos con 35.300 hectáreas ( 2,23 y $4,45 \%$ del total). En general, los fluvisoles calcáricos se localizan en el centro de la cuenca terciaria, mientras que los fluvisoles eútricos están en áreas más distales. Respecto a la capacidad potencial de uso agrícola de estos suelos corresponden a las clases A, B y C y, en muy baja proporción, a la D (ésta apenas es cartografiable). Hay que señalar que, aunque la $\mathrm{B}$ y $\mathrm{C}$ tiene más extensión que la $\mathrm{A}$, sin embargo ésta es la clase por excelencia de los fluvisoles, ya que casi todas las tierras de esta clase corresponden a fluvisoles, salvo dos pequeñas extensiones de calcisoles y luvisoles (una, en el Tajo, en el municipio de Aranjuez y, otra, en el Alberche al sureste de Villa del Prado). Así, casi toda la clase agrológica A corresponde a fluvisoles, aunque éstos pertenecen a las cuatro categorías mencionadas.

La extensión de fluvisoles con clase A es de unas 11.321 hectáreas. Esta clase no tiene apenas limitaciones, con capacidad de uso muy elevada, susceptible de una utilización agrícola intensiva. Son los más idóneos para cualquier uso, de ahí su gran riesgo. Se corresponden con la clase I y los mejores de la clase II del sistema americano (Klingebiel and Montgomery, 1961). Los suelos de clase A son un 2,20\% del total de suelos de la Comunidad de Madrid, de los que la mayoría corresponden a fluvisoles, puesto que en total son unas 17.500 ha. Se distribuyen en el corredor del Henares al este de la Comunidad, en el sur en la vega del tajo en las proximidades de Aranjuez y en el Alberche al sur del embalse de Picadas.

Los fluvisoles a los que se ha asignado la clase B ocupan 15.902 hectáreas aproximadamente, de las 100.000 ha que esta clase tiene en la Comunidad (un $12,84 \%$ ), y se asimilan a los suelos más pobres de la clase II americana y a la clase III. Aunque son suelos con una alta calidad agrícola ya tienen algunas pequeñas limitaciones debidas sobre todo a problemas de hidromorfismo o de erosión. Los limitados por hidromorfismo se distribuyen en el cauce del Guadarrama, en el Henares y la confluencia de este con el Jarama. Los suelos condicionados por erosión se distribuyen en una fina franja en la vega del Jarama y sus afluentes entre Talamanca y Barajas, el río Torote, el Tajuña, Tajo y Alberche.

La clase C correspondientes a la clase IV americana tiene unas 267.500 ha, 33,64\% del total de la comunidad de Madrid, de las que 15.924 hectáreas están en los fluvisoles. La mayoría tienen un uso condicionado por la proximidad de los niveles freáticos a la superficie. Se distribuyen en el Jarama, desde el límite provincial con Guadalajara hasta Coslada, (condicionado su uso por problemas de hidromorfismo) y en el Manzanares en el que su uso está condicionado por erosión.

La D (V y VI de la americana) es la clase que tiene más extensión en la Comunidad: 370.000 hectáreas (un 46,54\%), pero muy poca superficie corresponde a fluvisoles, sólo 9.108 hectáreas localizadas en pequeños sectores distales, en áreas deprimidas con fuertes limitaciones por hidromorfismo, próximas a los macizos montañosos. Son suelos con poco aprovechamiento agrícola. 
La clase E (VII y VIII de la americana, suelos muy pobres sin ningún aprovechamiento agrícola) ocupa 38.000 hectáreas (un 4,78\%), siempre en suelos desarrollados sobre los materiales paleozoicos de la sierra. Esta clase nunca se localiza en los fluvisoles.

Una vez establecida la proporción y distribución de las diferentes clases agrológicas en los fluvisoles, el siguiente paso es cuantificar la pérdida de suelo por sellado en esta unidad edáfica a lo largo de los veinte años y evaluar cómo afecta a cada una de las clases de capacidad potencial de uso agrícola. Para ello se ha cartografíado y cuantificado la superficie sellada en las imágenes de ambas fechas (Figuras 3 y 4). Los nuevos mapas generados se han superpuesto al mapa de clases agrológicas y se ha cuantificado la pérdida de suelo por sellado en cada una de las categorías.

En la tabla 1 se recogen las hectáreas selladas para cada fecha y el incremento entre ellas. El mayor incremento del sellado se ha producido en las dos clases que tienen más valor agrológico: A y $\mathrm{B}$ y, en porcentaje, el mayor incremento corresponde a la clase más fértil, clase A. Este sellado se debe fundamentalmente a la situación de estos suelos en las proximidades de grandes núcleos urbanos. Su desaparición implica, por tanto, la perdida de los suelos de mayor calidad.

Tabla 1. Sellado de fluvisoles en 1989 y 2009

\begin{tabular}{c|c|c|c|c|c} 
Clase & $\begin{array}{c}\text { Sup. total de } \\
\text { fluvisoles (ha) }\end{array}$ & $\begin{array}{c}\text { Sellado (ha) } \\
25-03-1989\end{array}$ & $\begin{array}{c}\text { Sellado (ha) } \\
20-06-2009\end{array}$ & $\begin{array}{c}\text { Incremento del } \\
\text { sellado (ha) }\end{array}$ & $\begin{array}{c}\text { Incremento del } \\
\text { sellado (\%) }\end{array}$ \\
\hline A & 11320,90 & 1102,64 & 1874,09 & 771,45 & 6,81 \\
\hline B & 15901,69 & 1611,08 & 2389,70 & 778,62 & 4,90 \\
\hline C & 15923,99 & 1148,62 & 1498,15 & 349,53 & 2,19 \\
\hline D & 9107,90 & 26,42 & 41,65 & 15,23 & 0,17 \\
\hline Total & 52254,60 & 3888,76 & 5803,54 & 1914,78 & 3,66
\end{tabular}

Fuente: elaboración propia

El incremento más acusado del sellado en la clase A se ha producido en los ríos Henares (proximidades de Alcalá de Henares, Azuqueca y Alovera), Tajo (alrededor de Aranjuez) y Jarama (en las proximidades de Mejorada del Campo y entre Titulcia y San Martín de la Vega).

La clase B ha tenido un importante incremento del sellado en las vegas del Jarama (entre Fuente el Saz y Coslada), Henares (proximidades de Torrejón y Alcalá), Manzanares (al sureste de la capital), Guadarrama (en el término de Boadilla del Monte) y Tajuña (al este de Titulcia).

El incremento más notable del sellado en la clase C se produce en el Jarama próximo a su unión con el Henares y en las proximidades de la desembocadura del Manzanares al sur de la capital. 
La evolución del sellado en la clase D es poco significativa en estas décadas, ya que la presión antrópica ha sido más pequeña al estar localizados lejos de los grandes núcleos urbanos. Además pocos fluvisoles corresponden a esta clase. De hecho, en la representación del mapa apenas es visible, por lo que se ha unido a la clase $\mathrm{C}$.

Figura 3. Sellado de las clases de capacidad potencial de uso agrícola en 1989

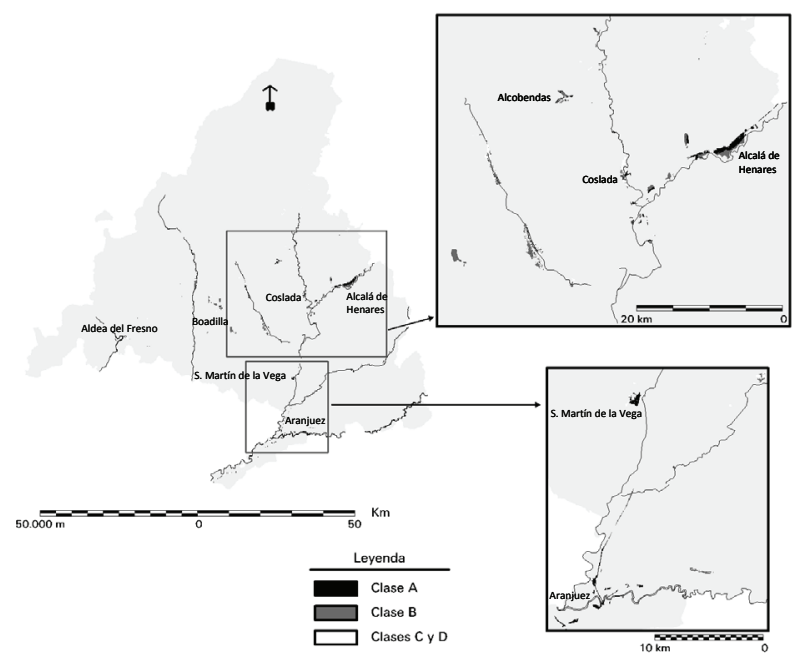

Figura 4. Sellado de las clases de capacidad potencial de uso agrícola en 2009.

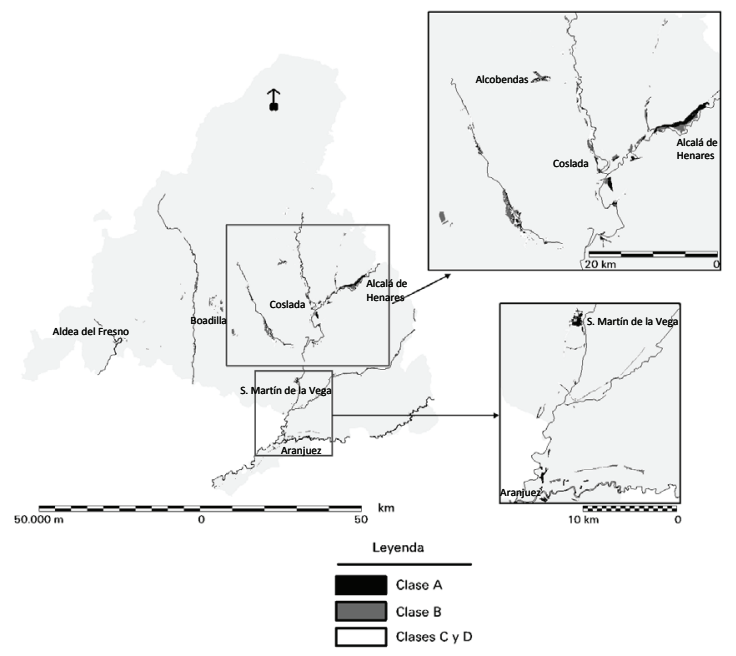

Fuente: elaboración propia 
Se ha realizado una clasificación automática siguiendo la regla de máxima probabilidad, ya que es la que ofrecía una mayor fiabilidad. Aún así, los valores obtenidos no coinciden exactamente con los de la cartografía manual, ya que este método calcula por defecto las superficies de fluvisoles (46.716 hectáreas, unas 8.000 ha menos que en la Tabla 1). Respecto a la evolución del sellado la clasificación supervisada considera selladas 2.161 hectáreas de los fluvisoles en 1989 y 5.284 ha en 2009 , cifras igualmente inferiores a las reales. Este error se origina, principalmente en residencias abiertas con amplios espacios verdes y en núcleos urbanos desarrollados sobre materiales calcáreo-margosos del sudeste de la Comunidad. Por ello, aunque requiera mayor elaboración, resulta más precisa la cartografía de suelos sellados elaborada mediante digitalización personal en las imágenes de satélite que con clasificaciones automáticas, incluso supervisadas.

Por último se ha efectuado un tratamiento digital para obtener una imagen sustrayendo a la imagen del sellado de suelos en 2009 la imagen del sellado en 1989. La imagen obtenida muestra el incremento del sellado en estas décadas (Figura 5). Este sellado es más notable en las confluencias de los ríos Henares y Jarama y de éste con el Manzanares y en algunos sectores del Guadarrama y del Tajo. También se ven pequeñas manchas en la vega del Tajuña, en el cauce del Torote y en el río Alberche al sur del embalse de Picadas. En todo caso, el sellado de suelos es mucho más significativo en las proximidades de los grandes núcleos urbanos.

Figura 5. Incremento del sellado en los fluvisoles entre 1989 y 2009

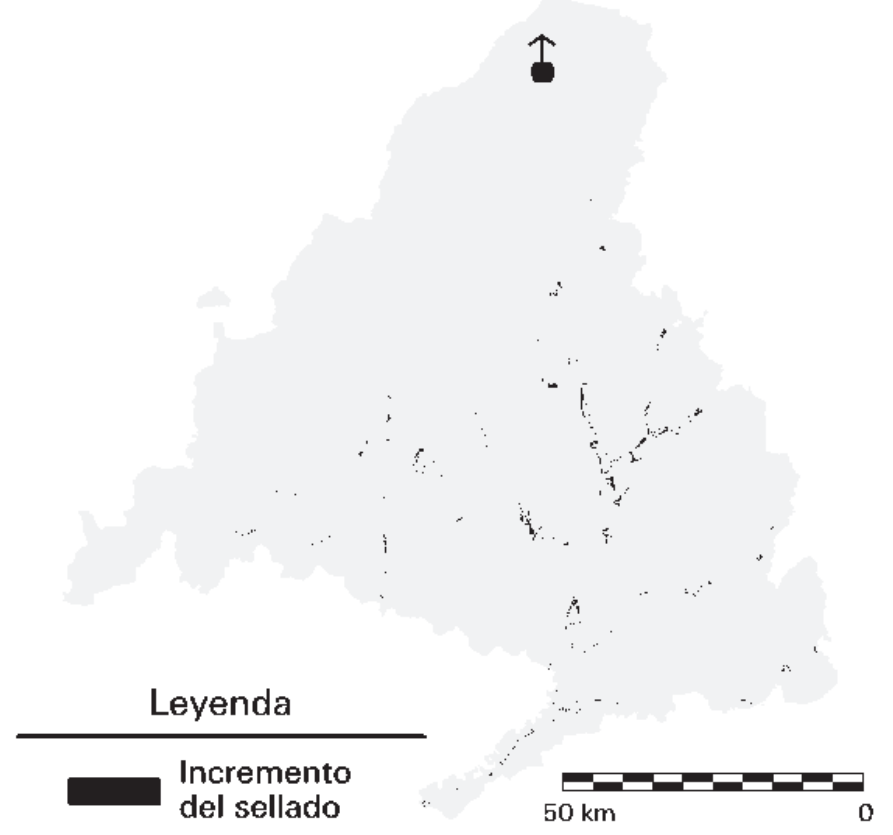

Fuente: elaboración propia 


\section{CONCLUSIONES}

Las imágenes del satélite Landsat son muy útiles para hacer un seguimiento de la evolución del sellado debido a su disponibilidad desde los años ochenta hasta la actualidad y a que su resolución espacial es idónea para cartografía de escala media.

Para obtener buenos resultados es conveniente realizar tratamientos digitales que combinen bandas visibles e infrarrojas, ya que detectan mejor los suelos sellados. Las mejores combinaciones de bandas son es la 5-3-1 y 5-3-2.

La cartografía de suelos sellados ofrece mejores resultados a partir de la digitalización de los suelos sellados en las imágenes de satélite, combinando el análisis visual con el tratamiento digital.

La cartografía automática requiere un conocimiento de la tipología del sellado y de las unidades edáficas, ya que si no introduce numerosos errores al cartografiar los fluvisoles puesto que calcula por defecto las superficies selladas. Esto indica que para discriminar correctamente los suelos sellados es necesario el conocimiento de la verdad-terreno, debido a la complejidad de la cartografía edafológica y de los usos potenciales de las clases agrológicas.

La perdida de suelo por sellado en la Comunidad de Madrid afecta sobre todo a suelos muy ricos agrícolamente: clases A y B.

La perdida más acusada se produce en las vegas de los ríos Jarama y Henares. Las cuencas del Manzanares, Guadarrama y Tajo también tienen pérdidas acusadas en las proximidades de los grandes núcleos urbanos.

El sellado de fluvisoles no sólo reduce las tierras fértiles de la Comunidad, si no que también constituye un grave riesgo medioambiental, ya que incrementa el riesgo de inundación por la pérdida de infiltración de estos suelos.

\section{BIBLIOGRAFÍA}

AÑÓ, C. y SÁNCHEZ, J. (2003): Orientaciones de uso agrario. Una metodología para la planificación de usos del suelo en la Comunidad valenciana. Biblioteca de Ciencias, 5. C.S.I.C. Madrid, 129 pp.

AÑÓ, C.; PASCUAL, J.A. y SÁNCHEZ, J. (2005): Capacidad de uso y sellado antropogénico del suelo en la franja litoral de la provincia de Castellón. Investigaciones Geográficas, 38: 65-77.

BIASIOLI, M.; BARBERIS R. \& AJMONE F. (2006):. The influence of a large city on some soil properties and metals content. Sci. Total Environ., 356, 154-164.

BLUM, W.E.H. (1998): Soil degradation caused by industrialization and urbanization. En H.P. Blume, H. Eger, E. Fleischhauer, A. Hebel, C. Reij y K.G. Steiner (edit.) Towards sustainable land use: furthering cooperation between people and institutions. Vol. I Advances in Geoecology, 31. Catena Verlag Reiskirchen: 755-766. 
BOUMA J. (2006): Soil functions and land use. En Soils. Basic Concepts and Future Challenges(G. Certini \& R. Scalenghe, Editors), Cambridge University Press. Cambridge, 211-221.

CASTILLO, V.; Vandekerckhove, L.; Jarman, R. (2004): Working Group on Soil Erosion Introduction. Final report. European Comisión, 23 pp.

EFFLAND, W.R. y POUYAT, R.V. (1997): The genesis, classification, and mapping of soils in urban areas, Urban Ecosystem, 1, 217-228.

GARCÍA RODRÍGUEZ, M ${ }^{\mathrm{a}}$ P; PÉREZ GONZÁLEZ, Mª. (2007): Changes in soil sealing in Guadalajara: cartography with Landsat images. Science of total Environment, 41, DOI: 10.1016/j.scitotenv.2007.01.048.

GARCÍA RODRÍGUEZ, Mํㅗ. y PÉREZ GONZÁLEZ, Ma E. (2010 a): Aplicaciones de la teledetección en Geografía Física en la Universidad Complutense de Madrid. Serie Geográfica, 16, 9 - 18.

GARCÍA RODRÍGUEZ, Ma P. y PÉREZ GONZÁLEZ, Ma E. (2010 b): Sellado de suelo en la Comunidad de Madrid entre 1989 y 2009. Estudio a partir de imágenes TM. En: Libro de Actas del IV Congreso Ibérico de la Ciencia del Suelo; Granada, 1160-1171.

IGN PLAN NACIONAL DE TELEDETECCIÓN (2009): pnt_landsat5 TM_201032_20090706_geo_xsbic_etrs89_hu30_gsd25_std.

IGN PLAN NACIONAL DE TELEDETECCIÓN (2010): pnt landsat5 TM_201032_20100506_geo_xsbic_etrs89_hu30_gsd25_std.

JIMÉNEZ SÁNCHEZ, M.A. (2000): Revista del aficionado a la meteorología http:// www.meteored.com/ram/804/las-inundaciones-en-la-comunidad-de-madrid/.

KLINGEBIEL, A.A. \& MONTGOMERY, P.H. (1961): Land capability classification. USDA Agricultural Handbook 210. US Government Printing Office, Washington.

MARTÍNEZ MARÍN, E. (2006): Las zonas inundables de la Comunidad de Madrid: análisis y cartografía. Ed. Comunidad de Madrid. Madrid 376 pp.

MONTURIOL, F. y ALCALÁ, L. (1990 a): Mapa de asociaciones de suelos de la Comunidad de Madrid. Escala 1:200.000. C.S.I.C., Comunidad de Madrid. $1^{\mathrm{a}}$ edición, Madrid, 71 pp.

MONTURIOL, F. y ALCALÁ, L. (1990 b): Mapa de capacidad potencial de uso agrícola de la Comunidad de Madrid. Escala 1:200.000. C.S.I.C., Comunidad de Madrid. $1^{\text {a }}$ edición. $31 \mathrm{pp}$. Madrid.

NASA LANDSAT PROGRAM, 2009, Landsat TM p201/r032/p201r32_5t19890325. TM-EarthSat-Orthorectified, USGS, Sioux Falls, 03/25/1989. 
NIZEYIMANA, E.L.; PETERSEN, G.W.; IMHOFF, M.L.; SINCLAIR JR.,H.R.; WALTMAN, S.W.; REED-MARGETAN, D.S.; LEVINE, E.R. \& RUSSO, J.M. (2001): Assessing the impact of land conversion to urban use on soils with different productivity levels in the USA, Soil Sci. Soc. Am. J., 65, 391-402.

SCALENGHE, R. y AJMONE-MARSAN, F. 2009. The anthopogenic sealing of soils in urban areas. Landscape and Urban Planning, 9,0 1-2: 1-10.

ZINCK, J.A. (1996): La información edáfica en la planificación del uso de la tierra y el ordenamiento territorial. En J. Aguilar, A. Martínez y A. Roca, Edit. Evaluación y manejo del suelo. Junta de Andalucía. S.E.C.S. Univ. Granada: 49-75.

Páginas webs citadas

http://ec.europa.eu/environment/soil/index.htm

http://www.eeb.org/press/2009/10Green-Tests-for-the-Spanish-Presidency_SP_Last-Version.pdf 